\title{
DIFFICULT ENTRY AND RETURN TO THE LABOR MARKET: ON THE PROFESSIONAL (RE)INTEGRATION OF PEOPLE WITH DISABILITIES AND CHRONIC HEALTH CONDITIONS IN POLAND (THE PATHWAYS RESEARCH PROJECT)
}

\section{ALEKSANDRA PIŁAT ${ }^{1}$, BARBARA WOŹNIAK ${ }^{1}$, BEATA TOBIASZ-ADAMCZYK ${ }^{1}$, MONIKA BRZYSKA ${ }^{1}$, MATILDE LEONARDI ${ }^{2}$, SABRINA FERRAINA ${ }^{3}$, and ASEL KADYRBAEVA ${ }^{3}$}

${ }^{1}$ Jagiellonian University Medical College, Kraków, Poland

Department of Medical Sociology, Chair of Epidemiology and Preventive Medicine

${ }^{2}$ Foundation IRCCS Neurological Institute Carlo Besta, Milan, Italy

${ }^{3}$ European Association of Service Providers for Persons with Disabilities (EASPD), Brussels, Belgium

\begin{abstract}
Objectives: The objective of this study is to present the barriers existing in Poland to professional integration and reintegration of people with chronic diseases, including mental health conditions, and discuss them on the basis of expert opinions and in comparison with the situation in other European countries. Material and Methods: The research methodology was based on a mixed-methods approach, including literature review, in-depth expert interviews, and a survey (based on a structured questionnaire) performed with experts. Results: The mapping of policies, systems and services facilitating the integration and reintegration of people with chronic diseases in Poland, as well as expert opinions, made it possible to identify many barriers regarding access to support, such as an obligation to have a certificate of disability, and a system of certification by 2 institutions. There are also barriers regarding the support itself, including problems with subsidies and with professional (re)integration services. Conclusions: Poland has a multilevel and multi-sector system of public institutions, which should provide support for people with disabilities and chronic diseases. Nevertheless, the research conducted in Poland indicates an insufficient implementation of the existing solutions. Int J Occup Med Environ Health. 2019;32(4):475-88
\end{abstract}

Key words:

disability, Poland, vocational rehabilitation, employability, labor market, chronic conditions

Funding: this study was supported by the European Union's Health Programme (2014-2020) (project No. 663474, entitled "Participation to healthy workplaces and inclusive strategies in the work sector, PATHWAYS," project manager: Matilde Leonardi, Ph.D.) and by the Ministry of Science and Higher Education (grant No. 3649/ HP3/16/2017/2, grant manager: Prof. Beata Tobiasz-Adamczyk).

Received: April 20, 2018. Accepted: March 14, 2019.

Corresponding author: Aleksandra Piłat, Jagiellonian University Medical College, Department of Medical Sociology, Chair of Epidemiology and Preventive Medicine, Kopernika 7a, 31-034 Kraków, Poland (e-mail: aleksandra.pilat@uj.edu.pl). 


\section{INTRODUCTION}

"PArticipation To Healthy Workplaces And Inclusive Strategies in the Work Sector" (PATHWAYS) is an international project, co-funded by the Health Programme of the European Union, coordinated by the Neurological Institute Carlo Besta in Milan, Italy. The project gathers together health scientists representing various professions (physicians, psychologists, medical sociologists, etc.) from 10 European countries (Austria, Belgium, Czech Republic, Germany, Greece, Italy, Norway, Poland, Slovenia, Spain). The PATHWAYS project aims to contribute to the development of innovative approaches to promote professional (re)integration of people with chronic diseases (PwCDs) that are rarely studied in the context of their influence on work ability and employability of the patients, namely depression, headaches (migraine), diabetes, musculoskeletal disorders, chronic obstructive pulmonary disease (COPD), and cardiovascular diseases.

Work ability [1] is a complex issue that results from a combination of different factors, including individual-level factors (such as education, skills, motivation, etc.) and workplace-related factors (e.g., physical and mental work demands, management or physical work environment). The project aims to increase occupational activity of PwCDs on the labor market, inter alia, through improving their work ability.

On the one hand, a poor health condition could be associated with a higher risk of unemployment and treated as a possible source of adverse consequences for self-rated health, as well as physical and psychological well-being. Nevertheless, not all people of working age have the same opportunities to enter (preoccupation health selection) and remain on the labor market. A specific group is formed by people with disabilities (PwDs), PwCDs and people with mental disorders, considering the issue of social selection and employers preferences towards more effective workers.

On the other hand, in the course of performing occupational activity, the occurrence of specific diseases, espe- cially chronic conditions, could significantly change the work course and position of active workers, cause limitations in their ability to perform previous work or even the necessity to leave work, and change their occupational status from an active worker to a passive pensioner.

The prevalence of chronic conditions in the current epidemiological structure of diseases poses challenges for medical practitioners, associated with controlling the disease process, and offering such treatments which give a chance to minimize the biological and psychosocial consequences of the disease, and the limitations caused by the actual heath status, as well as make it possible to return to or continue previous social roles, especially the occupational one. In the strategies of coping with chronic conditions and disabilities, special attention in several concepts has been paid to occupational activity, because most people spend a major part of their lives in the working environment, with employment constituting an important dimension of an adult's life. It not only provides material resources (income) but also significantly influences the general social status in relation to the level of education, professional skills, as well as the sense of engagement, social identification, participation in social networks consisting of different groups of co-workers, and physical as well as mental stimulation [2,3]. Occupational activity can contribute to mental well-being, as well as increase the sense of belonging and social integration. People who are employed declare higher self-esteem which depends on the value of work-life satisfaction and self-realization. In the case of re-employment, a return to paid employment improves one's self-rated health in a short time [4].

Changes in the health status, especially associated with long-term chronic conditions and disability, along with long-lasting sickness absence, can trigger the necessity to give up work. However, in terms of the "response shift theory" [5], many of the existing chronic conditions, after systematic treatment and health assessment, give individuals an opportunity to adopt to new health con- 
ditions by learning new patterns of functioning in new health-related circumstances.

The issues of controlling the course of chronic conditions by modern medicine, developing a new social circumstance, are associated with the general position of chronically-ill people on the labor market. It also appears advisable to perceive that problem from a long-term perspective and inquire about the extent to which the position of people with chronic conditions, living in different countries (also in Poland), depends on the socio-economic circumstances and whether they have the same chance to continue or return to the previous occupational activity, or be involved in another forms of such activity. The question should, therefore, be asked of whether the existing patterns on the labor market provide opportunities for chronically-ill people, and what should be done within the social policy framework to improve their participation in occupational activity.

\section{Barriers in the assessment of the existing situation - the question of the definition}

Disability can be defined in a number of ways, although a more standardized definition of disability has been established by the World Health Organization (WHO), which covers impairments, activity limitations and participation restrictions [6]. The definition and measurement of PwDs play a key role in elaborating on the employment issue [7]. Depending on the definition and measurement of the population of PwDs, there is a different number of the disabled, especially in the context of employment. This can be clearly observed on the example of Poland, where at least 2 definitions of the disabled are currently in use. The first definition arises from legal regulations, and the second is a broader definition covering people with the subjective feeling of limitations in everyday activities. The second comes from self-assessment of the health status, so it covers not only people with a certificate of disability but also those with self-reported limitations in some activities.
The International Classification of Functioning, Disability and Health (ICF) has marked an attempt to establish a common language used to describe health and healthrelated conditions, including disabilities [8-10]. The ICF is based on a modern definition of disability, and refers to both medical [10] and social models of disability [11]. According to the ICF, disability is a complex phenomenon that is both a problem at the level of a person's body, and a complex and primarily social phenomenon [12]. It consists of interactions between the health condition and contextual factors, such as environmental and personal determinants. The ICF model identifies 3 levels of human functioning, i.e., the level of the body or body parts, the whole person, and the whole person in the social context [13]. The usefulness of this tool is particularly important from the social policy perspective, because it allows planning interventions, strategies and programs in the area of disability, including people with disabilities on the labor market.

\section{Assessing the number of people with disabilities (PwDs) and people with chronic diseases (PwCDs)}

According to the Central Statistical Office in Poland, there are 7.7 million people with self-reported disabilities, including 3.8 million Poles with a legal certificate of disability [13]. This means that every 10th Pole has a legally confirmed disability. The certification of disability levels (severe, moderate or mild) regulates such issues as the amount of compensation for employees, funding for the salaries of people with disabilities, and many others. Despite the fact that some solutions have been in place, the number of people with disabilities on the labor market is still low.

According to the most recent data available from the Labor Force Survey in Poland, the activity rate for people with disabilities (16+) equals $16.3 \%$, compared to $56 \%$ for people without disabilities (15+) [14]. The employment rate, defined as a measure of the extent to which the available labor resources are being used, indicates that only $15.2 \%$ of people with disabilities are currently working (in 
comparison to $53.7 \%$ of people without disabilities). The outcome of this situation is a higher unemployment rate among people with disabilities (6.6\%) than among ablebodied people (4.2\%) [14]. Moreover, disabilities and diseases constitute the third most common reason for being professionally passive, preceded only by retirement and the acquisition of knowledge, skills/qualifications [15].

The most frequently declared chronic diseases for both women and men include back and neck pain, migraine and diabetes [16]. In Poland, $>8$ million people suffer from back pain and 3.5 million have diabetes, whereas migraine is a chronic disease affecting 2.5 million Poles. Other frequently occurring chronic diseases are COPD which is recognized among 2.5 million Poles, coronary artery disease (CAD) diagnosed among 2.9 million, and depression with the number of cases oscillating around 1.2-1.5 million. Being professionally passive contributes to a financial burden for the country. An average number of people receiving a disability pension in 2015 was about 1 million, and the average number of people receiving a family pension was 1 million 265 thousands [17].

Currently, 52\% of Poles report a long-standing illness which has lasted for at least 6 months, and it is worth to mention that $80 \%$ of the causes of disability are related to chronic diseases [15].

\section{Aim of the paper}

This paper is focused solely on the results regarding policies, systems and services existing in Poland. The most important and influential solutions (in terms of their impact on the situation of people with limited capability for work) were selected to be presented and discussed here.

The presented paper is based on the findings from the first stage of the PATHWAYS project. The objective of this study is to present the barriers existing in Poland to professional integration and reintegration of persons with chronic diseases, including mental health conditions, and discuss them on the basis of expert opinions and in comparison with the situation in other European countries. The existing Polish solutions were critically analyzed with respect to effectiveness of the (re)integration of the people with specific disabilities and chronic conditions to the labor market.

\section{MATERIAL AND METHODS}

The first stage of the PATHWAYS research project was aimed at the identification of solutions existing in the partner countries, related to professional (re)integration of people with chronic health problems. The analytical concept of the study is illustrated in Figure 1. Three types of strategies were studied, including policies (i.e., legislations, policies), systems (i.e., programs, schemes) and services (e.g., activities to assist job seekers), addressed to people with health problems, regarding their participation in, and (re)integration to, the labor market. As in most regulations PwCDs are considered as PwDs, this group, as the largest, was also taken into account in the study. The research methodology was based on a mixed-methods approach, including document analysis, in-depth expert interviews, and a survey (based on a structured questionnaire) performed with experts.

The document analysis was focused mainly on the analysis of the policy documents and other publications concerning policies, systems and services in Poland. Each partner made a list of the legal and political solutions existing at the moment of conducting the research at the national or local level, and regulating the situation of PwCDs/PwDs on the labor market. The documents were searched for on the Internet. Any document concerning the issue under examination was included in the analysis (but the presented paper is focused only on the most important regulations). The documents were categorized into 3 types, namely policies, systems and services (Figure 1).

The second step focused on the distribution of the developed questionnaire to national experts (e.g., policymakers, service providers, physicians having expertise in the diseases under examination, etc.) (Table 1), representing 


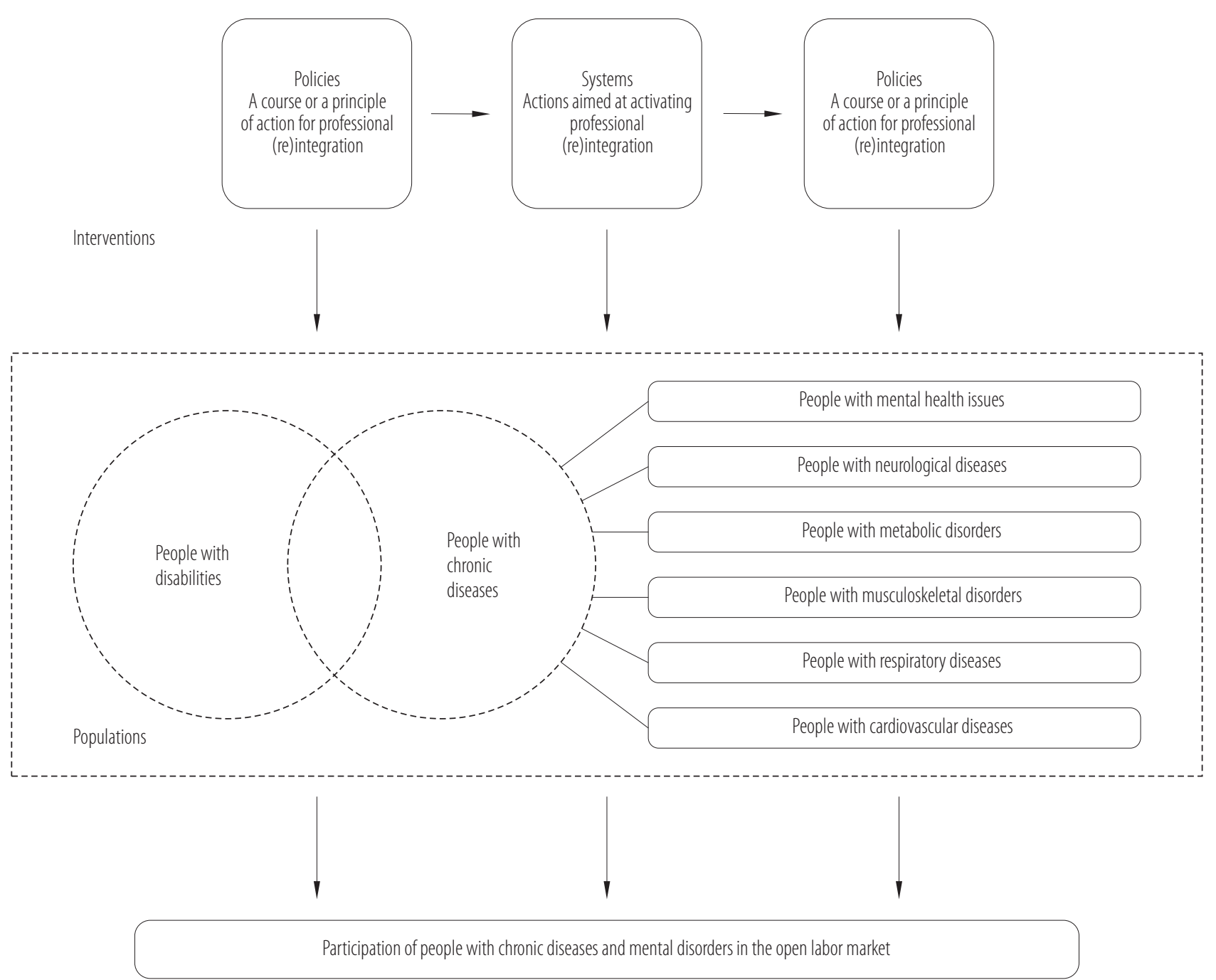

Source: D4.1. A report on the comparison of the available strategies based on 5 categories of social welfare models in Europe, an internal report in the PATHWAYS project developed by EASPD [17].

Figure 1. The analytical scheme followed in the first stage of the PATHWAYS research project

organizations working in the field of professional (re)integration of people with the diseases under examination in the PATHWAYS project $(\mathrm{N}=10)$. The questionnaire was divided into 3 parts:

1. General information about the respondent (e.g., organization details, provided services in the field of employability of PwCDs),

2. Information on national-level legislations regulating the employment of PwCDs/PwDs (e.g., what kind of support is provided in the country for both PwCDs/ PwDs and employers, legal solutions and provisions, existing gaps in the legislation),

3. Information on the disease/disability-specific legislation, schemes and services.

To eliminate all the possible gaps appearing in the questionnaire in the third step, expert interviews (semi-structured) ( $\mathrm{N}=3$ /country) were conducted among representatives of public, private and non-governmental organiza- 
tions (NGOs) providing professional (re)integration support to people with limited capability for work. There were 3 versions of the interview scenario: for the authorities, service providers and self-advocates. The tool covered the following sections:

- general information about the respondent,

- information about the existing strategies,

- opinions about them.

Information about the study participants is available in Table 1.

Each of the research techniques employed in the project was aimed at eliciting information about the policies, sys- tems and services existing in each partner country. The gathered information made it possible to create a model of barriers identified in the Polish system of professional (re)integration (Figure 2). Finally, the SWOT (strengths, weaknesses, opportunities and threats) analysis (Figure 3) was performed in order to summarize the results based on reviews and expert opinions. The SWOT analysis highlighted the most important results, presenting the strengths and opportunities, as well as threats and weaknesses, of the solutions existing in Poland and regulating the situation of people with disabilities and chronic conditions on the labor market.

Table 1. Polish participants $(\mathrm{N}=13)$ in the PATHWAYS research project conducted in 10 European countries (Austria, Belgium, Czech Republic, Germany, Greece, Italy, Norway, Poland, Spain and Slovenia) in 2015-2018

\begin{tabular}{|c|c|c|c|}
\hline Expert & Organization & Position & Study type \\
\hline Expert 1 & NGOs "Defeat cancer" & $\begin{array}{l}\text { representative, } \\
\text { chemist }\end{array}$ & e-mail survey \\
\hline Expert 2 & university office for PwDs & leader & e-mail survey \\
\hline Expert 3 & $\begin{array}{l}\text { Association for Development } \\
\text { of Community Psychiatry and Care }\end{array}$ & psychiatrist & e-mail survey \\
\hline Expert 4 & university hospital & physician & e-mail survey \\
\hline Expert 5 & $\begin{array}{l}\text { department of metabolic diseases, } \\
\text { university hospital }\end{array}$ & physician & e-mail survey \\
\hline Expert 6 & $\begin{array}{l}\text { chair of General Surgery and } \\
\text { Department of General Surgery, } \\
\text { Oncology and Gastroenterology }\end{array}$ & physician & e-mail survey \\
\hline Expert 7 & $\begin{array}{l}\text { National Union of the vocational } \\
\text { rehabilitation facilities and public } \\
\text { enterprise }\end{array}$ & manager & e-mail survey \\
\hline Expert 8 & $\begin{array}{l}\text { MATIO Foundation for Families } \\
\text { and Patients with Cystic Fibrosis }\end{array}$ & physiotherapist & e-mail survey \\
\hline Expert 9 & $\begin{array}{l}\text { Jagiellonian University } \\
\text { Medical College }\end{array}$ & physician & e-mail survey \\
\hline Expert 10 & $\begin{array}{l}\text { municipal labor office - department } \\
\text { of stimulation of disabled people }\end{array}$ & career advisor & e-mail survey \\
\hline Expert 11 & Marshall office & policy maker & expert semi-structured interviews \\
\hline Expert 12 & foundation & service provider & expert semi-structured interviews \\
\hline Expert 13 & Polish Association of Disabled People & self-advocate & expert semi-structured interviews \\
\hline
\end{tabular}

NGOs - non-governmental organization(s); PwDs - people with disabilities. 


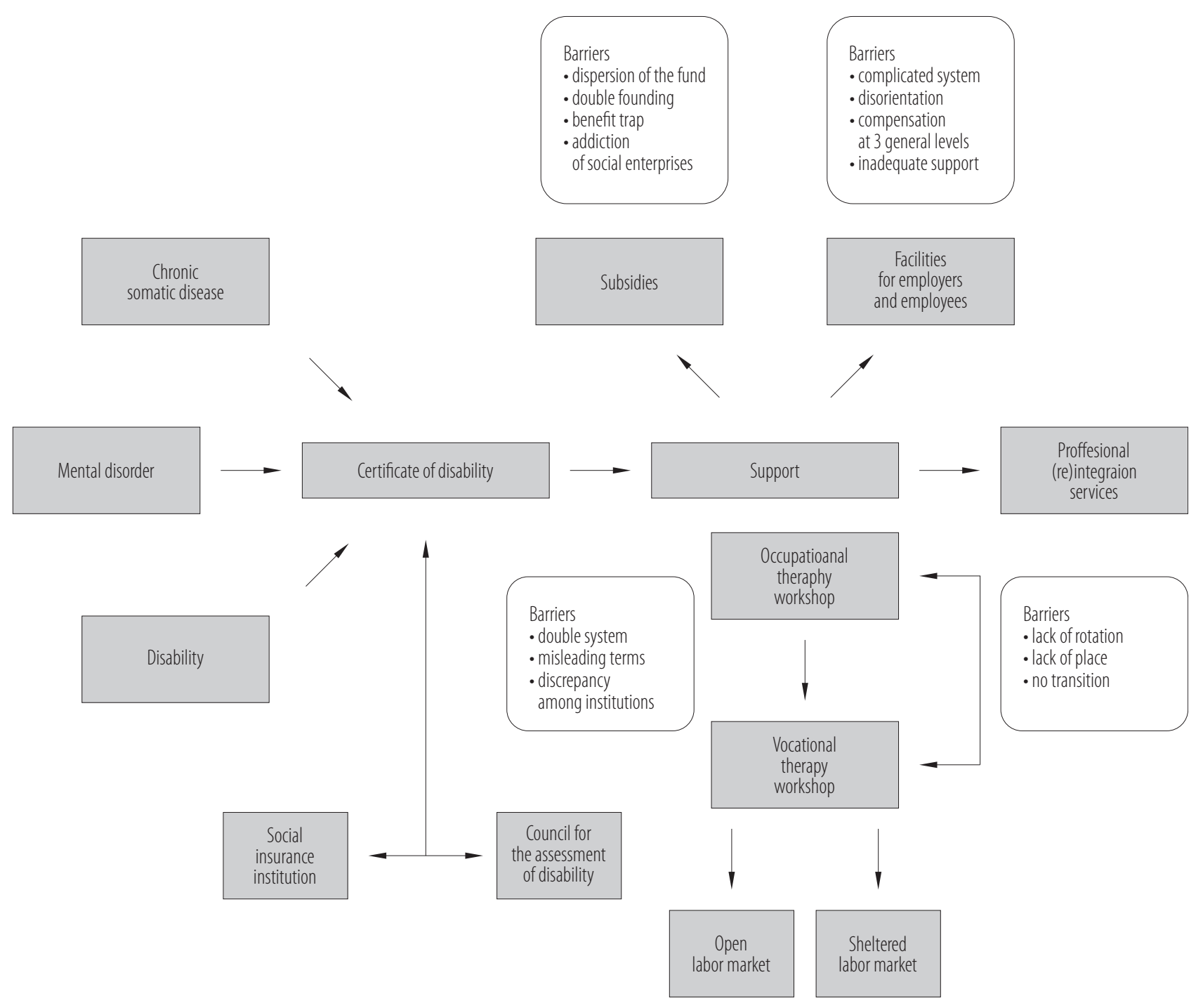

A model developed by the authors on the basis of the PATHWAYS research.

Figure 2. A system of professional (re)integration and barriers identified by experts

\section{Ethical approval}

All procedures performed in the studies involving human subjects were in accordance with the ethical standards of the institutional and/or national research committee, and with the 1964 Helsinki Declaration and its subsequent amendments, or comparable ethical standards.

The Bioethical Commission approval number is 122.6120.222.2016; the document was issued on June 27, 2016.

\section{RESULTS}

\section{Barriers to professional (re)integration} identified in Poland

The analysis based on a mixed-methods approach made it possible to develop a model (Figure 2) to visualize the Polish system of support for PwCDs/PwDs, and the main barriers existing within it, limiting access to this support, such as an obligation to have a certificate of disability, and a system of certification by 2 institutions. Obtaining 


\begin{tabular}{|c|c|}
\hline $\begin{array}{l}\text { Strengths } \\
\text { - the existing variety of legal solutions focused on the (re)integration of people with certified } \\
\text { disabilities } \\
\text { - a growing number of occupational therapy workshops and vocational therapy workshops } \\
\text { - the existing systemic mechanism of financing the (re)integration of people with disabilities }\end{array}$ & $\begin{array}{l}\text { Weaknesses } \\
\text { - the lack of solutions targeted at people suffering from chronic conditions } \\
\text { but not having the certificate of disability } \\
\text { - the lack of specificity in terms of causes of disability } \\
\text { - solutions targeted at already active individuals } \\
\text { - the lack of an empowerment approach and a person-centered approach } \\
\text { - the inconsistency of existing solutions (e.g., the benefit trap) } \\
\text { - the lack of an integrated services approach } \\
\text { - the lack of an evidence-based approach (evaluation) }\end{array}$ \\
\hline $\begin{array}{l}\text { Opportunities } \\
\text { - increased financing through the EU and targeted projects aimed at (re)integration } \\
\text { (e.g., training programs targeted at the development of skills) } \\
\text { - the developing sector of NGOs in Poland } \\
\text { - the growing sector of patients advocacy groups focused on (re)integration } \\
\text { - the development of disability studies in Poland and scientific research in this field } \\
\text { - the rising awareness of work-related problems among people with disabilities } \\
\text { and chronic conditions and the "new identity of disabled people" } \\
\text { - the growing number of well-educated young people with disabilities }\end{array}$ & $\begin{array}{l}\text { Threats } \\
\text { - the stigma surrounding work ability and productivity of people with disabilities } \\
\text { and chronic conditions } \\
\text { - the low level of education among disabled people } \\
\text { - the lack of motivation to work on the part of people with disabilities }\end{array}$ \\
\hline
\end{tabular}

Figure 3. A SWOT analysis of the solutions existing in Poland, identified in the paper

the certificate entitles one to receive support in the main 3 aspects:

- subsidies,

- facilities for both employers and employee,

- services for professional (re)integration, such as occupational therapy workshop (OTW) and vocational therapy workshop (VTW).

The main barriers to this support, as identified by professionals, are briefly described below.

\section{Policies}

According to the experts, in Poland there are no legal frameworks specifically addressing the needs of people with chronic somatic diseases. People with non-communicable chronic diseases (NCDs) are considered a group with special needs only if they have a disability certificate. The certificate also constitutes a prerequisite for any supporting programs, "These must be people who have a disability certificate. This is the basis. They must have a certificate from the Social Insurance Institution or the Council for the Assessment of People with Disabilities. They must be legally recognized as disabled" (Expert 12).
People with mental health conditions, whose situation has been partially regulated by the National Mental Health Protection Programme [18], but not in the context of employment, constitute no exception. According to a mental health expert, all kinds of support on the labor market depend on having a certificate of disability, "Persons from the selected group [mental disorder] are not singled out, but they are covered by a broader legislation applicable to persons with disabilities" (Expert 3).

Other barriers identified during the review, as confirmed by the experts, are problems with the double disability certification system. In Poland, there are 2 systems with different nomenclatures. In the Act on Old-Age and Disability Pensions from the Social Insurance Fund, and the Act on the Social Insurance System [19], the following terms appear: "inability to work" and "inability to live independently/need for long-term care" [19]. Such terms are misleading as "employers often think that people classified to these categories cannot work at all" (Expert 2). A crucial issue is the difficulty with obtaining a certificate of disability due to discrepancies among institutions or even regions, "It should be emphasized that an expert opinion is crucial and the same type of disability may be 
qualified at different levels in different parts of the country" (Expert 1).

People who already have a certificate of disability can get legal support. The legislative frameworks on disability and employment are mainly described in the Act on Vocational and Social Rehabilitation and Employment of Persons with Disabilities (of 27 August 1997) [20]. The Act governs the anti-discrimination policy and motivation for employers to hire PwDs, as well as regulates the rights and responsibilities of both employers and their employees (PwDs). One of the main incentives for employers who hire persons with limited capability for work is receiving compensation for the potential loss in productivity, "but it is very problematic to receive a compensation. Many effective employers resign from the compensation" (Expert 3). Another legal act which regulates the issues of disability and employment is the Labor Code [21]. The Code is mostly focused on anti-discrimination issues and equal treatment of all employees (including PwDs), and the solutions it envisages should also indirectly improve the situation of PwDs. Nevertheless, the reference regulations do not take into account the diversity of needs expressed by people with different types of disabilities and diverse chronic diseases, "No (legal) interpretation regarding the possibility of professional integration of people with hypoglycemia" (Expert 5).

\section{Systems}

The crucial support for professional integration with respect to subsidies is the State Fund for Rehabilitation of Disabled Persons (PFRON). The Fund operates under the Act on Vocational and Social Rehabilitation and Employment of Persons with Disabilities [20]. The aim of the Fund is to support the vocational and social rehabilitation and/or employment of disabled persons.

The PFRON funds are allocated, inter alia, to compensations for employers (on both the sheltered and open labor market), intended to cover the additional costs of employing disabled people (subsidies for salaries); reimbursement of the costs of workplace adaptation and equipment for employees with disabilities; financing of the establishing and operation of occupational therapy workshops and vocational rehabilitation facilities; outsourcing of non-governmental organizations and foundations' tasks in the field of professional and social rehabilitation of persons with disabilities; co-financing of system projects implemented from the EU funds; and providing support for individuals with disabilities. These tasks are usually divided between different institutions and regions, which leads to dispersion and difficulties with understanding who is responsible for what, "I know that NGOs find it problematic to reach the most appropriate entity to find the funding source to solve a specific problem" (Expert 11). The reimbursement of costs, both of workplace adaptation and equipment, and salaries for certified PwDs, takes into account the level of disability (severe, moderate or mild). However, these 3 general levels of disability cannot consider individual needs and barriers in the workplace of people with non-communicable diseases (NCDs) [22].

According to the experts, a disability or chronic disease is not always a problem for the labor force, owing to modern technologies, "Workplace adaptation and home offices could constitute effective solutions for people with NCDs" (Expert 13). In this case, the funds intended for salary reimbursement or regulations have not worked out. In the experts' opinion, this money should be better targeted and spent, for example, on training and further education.

One of the experts also indicated the problem with double funding, which constitutes a huge problem, inter alia, for NGOs. For instance, the funds intended for the same purpose, such as the adaptation of infrastructure to the needs of the disabled, can be obtained from 2 different sources. "Our statutory aim is to finance construction works, such as building and adaptation of rehabilitation facilities, and there is another institution (PFRON) that has a goal to 
reduce the architectural barriers and potential beneficiaries" (Expert 11).

In consequence, institutions do not actually know where they should apply for money. The respondents also pointed to the complexity of the funding system. The experts claimed that employers sometimes resign from reimbursement or workplace adaptation due to disorientation, "It happens that employers even resign from this fund!" (Expert 13).

The analyzed documents, as well as expert opinions, show that the financial support in Poland is concentrated around government subsidies, rather than social investments [15]. According to one of the experts, social enterprises are "addicted" to subsidies and benefits, "They (vocational rehabilitation facilities) are less motivated than other companies to sell the goods and services they produce at favorable prices. In other words, they are not interested in maximizing their profits" (Expert 11).

Their income could not be invested in the growth of the company or used in any other way. The whole profit earned from their work is intended for the Fund (PFRON). The significance of subsidies as a barrier was articulated both in the reviewed documents and during the interviews. The interviewed experts referred to the "benefit trap" as a barrier to professional (re)integration of PwDs. They described it as a situation in which a person receiving benefits does not undertake professional activity for fear of losing these benefits.

\section{Services}

The most important support tools of the professional (re)integration of people with limited capability for work to the labor market include occupational therapy workshops, vocational rehabilitation facilities and sheltered workshops. The purpose of rehabilitation carried out by means of occupational therapy workshops is the overall development and improvement of the efficiency of participants, necessary to lead an active and independent life. The purpose of the workshop is to gradually gain indepen- dence - from learning independently, through performing daily activities and social independence, to taking up employment. PwDs completing the workshop (and reaching a good level of social rehabilitation) should be transferred and employed in a vocational rehabilitation facility.

The assumption is that the OTWs are the first step in the professional rehabilitation and integration process, where social rehabilitation and self-efficacy building are combined with activities aimed at professional activation. The subsequent stage involves activities at the vocational rehabilitation facilities (VRFs), where social and professional rehabilitation are still carried out together, but from that moment the disabled person is professionally active and works for a given enterprise. Vocational rehabilitation facilities offer individual development and activation programs tailored to the needs of the disabled, and there are special commissions evaluating their development. When a PwD reaches the next level of professional development, he/she should be transferred to the open labor market or - if unable to go there - start working in a sheltered workshop. The reviewed documents show that VRFs and OTWs do not constitute a coherent system. One of the experts said, "It is still Utopian to think that they would go further, beyond the VRFs" (Expert 11). The reviews as well as expert opinions indicate the lack of rotation between OTWs, VTWs and the labor market. In consequence, those institutions are overfilled, and there are no free places for new PwDs.

Sheltered workshops, in turn, are not focused on transition to the open labor market, as they are designed for those people with disabilities who are unable to work beyond the sheltered work sector. The status of a sheltered work unit is given by the province governor by way of an administrative decision.

Based on the results of the documents analysis, as well as the in-depth interviews and the survey performed with experts, the authors were able to present the existing solutions as the SWOT (strengths, weaknesses, opportunities and threats) analysis. 


\section{DISCUSSION}

The objective of this study was to identify the existing barriers to professional (re)integration of PwCDs in Poland. The mapping of policies, systems and services facilitating the integration and reintegration of PwCDs in Poland has revealed that Poland has a multi-level and multi-sector system of public institutions, which should provide support for people with disabilities. The institutions should guarantee effective services adjusted to the needs of people with all kinds of disabilities or chronic diseases, and ensure their full functioning in the society. Nevertheless, the research conducted in Poland indicates an insufficient implementation of the existing solutions. Moreover, there are persistent symptoms sustained by institutional arrangements, which have repeatedly confirmed that they are inefficient and lossmaking, as well as constitute a barrier rather than support. The obligation to hold a certificate of disability is the first barrier to professional (re)integration. The certificate constitutes a prerequisite for systemic support. It means that, in terms of any support, PwCDs are considered part of a group of persons with disabilities. This barrier is escalated by terminological discrepancy, the 3 general levels of disability, and the way disability is defined. This issue has also been identified in other European countries [22]. Recent research has indicated that the occupational needs of chronically-ill people differ from those of PwDs. This diversity mainly concerns the presence of pain, fatigue, problems with motor control or cognitive functioning [23]. To be more precise, the existing studies have proven that depression has the largest impact on every work area, migraine and diabetes impact on cognitive work demands, and musculoskeletal pain mainly affects physical work demands [24]. The results suggest that every chronic disease has some specific demands regarding the workplace, which should be recognized in order to provide the most effective environment for PwCDs.

Voojis et al. [25] point out the necessity to strike an intervention balance between focusing on personal abilities and job demands. This paper shows the ineffectiveness of intervention due to a generalized approach and inapplicable regulations. The PFRON system, on the one hand, adjusts the working environment to the needs of people with disabilities but, on the other hand, these solutions are generalized, as they are not focused on a specific disease, but on the 3 general levels of disability. The same requirements and duties have to be fulfilled by employers who hire people with various diseases, regardless of the reason behind issuing a certificate of disability. Hence, the systemic solution and services are aimed at adjusting people with chronic diseases to the employers' expectations, instead of adapting the workplace, employment and employment practices to the needs of disabled or chronicallyill staff. Due to the lack of solutions for specific somatic and mental chronic diseases, the 3 general levels of disability fail to promote a holistic approach focusing on both personal attitude and job demands. In consequence, the Polish support system has been identified as deficient. The adequacy of the solutions aimed also at individual needs has been confirmed in the review, which shows that effective return-to-work and vocational rehabilitation interventions depend, inter alia, on the support's being tailored to individual needs [26].

Two disturbing mechanisms with regard to subsidies support have been identified. Both of them make PwDs more dependent on the financial support and discourage them from entering the labor market [22]. First, people with a certificate of disability are afraid of losing the status of a person unable to work, as this would lead to falling into the "benefit trap" [27]. Research conducted in Poland has indicated that more than a half of the studied population is more or less convinced that being employed results in losing the disability pension [28]. The benefit trap as a barrier in return to work has also been shown in randomized research conducted on people with mental disorder [29]. Addiction to subsidies has also been noted as regards social enterprises. The research has suggested that the lack 
of motivation is a consequence of the need to transfer the whole profit to the Fund (PFRON). Motivation-oriented solutions exist, for example, in the Netherlands where the policy focus is on the idea that labor participation contributes to the well-being of both individuals and the society. It means that disability benefits have been tightened for people as a stimulation for their return to work [30]. In another study, also conducted in the Netherlands, researchers have explored solutions that facilitate participation in the labor market. These solutions are focused either on the people themselves, such as accepting and coping with the disease, or gaining an insight into what they are currently capable of, or on their job and workplace, e.g., making adaptations to the workplace [31].

Consequently, most of the people with chronic diseases and/or disabilities are not employed at all. This is reflected by the low employment rate among PwDs. This may lead to social exclusion and economic dependence. Policy strategies, systemic solutions and services play the most important role in supporting the employment of people with chronic diseases. Protection against social risks, such as unemployment, should be one of the priorities of social welfare. It is important both from the economic point of view and for individuals, as continuing activities during a chronic disease is more effective in reducing pain than traditional medical treatment [27]. A good example is set by people with low back pain, who are able to continue working or to return to work within a few days or weeks, even with residual or recurrent symptoms [28]. All the more, the need to implement strategies helping people with specific chronic diseases to pursue their professional reintegration is urgent in the whole European Union. It was reflected in the Europe 2020 Strategy which highlights the necessity for the participation of all workingage people in the labor market [32], given especially that people with long-standing health problems experience a higher economic unemployment rate and only $19.7 \%$ of them are employed [33].

\section{Limitations}

The presented research tackles an important issue that is rarely studied in the European context. This article will contribute to the discussion on the situation of PwCDs/ PwDs on the labor market. However, there are some limitations of this study that should be mentioned. First of all, the survey sample is not representative. Moreover, the study is focused exclusively on the experts' perspective (the PwCDs/PwDs' perspective will be analyzed in a separate paper). The issue under examination requires further investigation on larger samples. It is also worth mentioning that although this paper presents only the situation in Poland, the comparative data for Europe, based on the PATHWAYS project results, are available [22].

\section{CONCLUSIONS}

The actual health condition is not the only reason why PwCDs withdraw from the labor market and do not decide to return after treatment and adaptation to their new status. The most important factors are the lack of adequate support, systemic barriers, and ineffective services not tailored to individual needs.

The problems with the support for people with disabilities, as identified in the PATHWAYS project and proven by the results of other studies, have shown that policies, systems and services should develop in the direction of an active policy. They should be aimed at promoting the employment of people with chronic diseases, and at encouraging both employers and potential employees to cooperate. Overcomplicated systems do not encourage employers to hire people with disabilities. The support system should, therefore, be simplified and, at the same time, its promotion is necessary. The most important thing is that the employer should know that hiring a person with disability is profitable. Another crucial recommendation concerns more flexible subsidies and higher motivation for social enterprises. If there is a real support on the labor market for people with chronic diseases, people with mental 
health problems and people with disabilities, employers will manage to respond to the need for employment among these groups. According to the interviewed experts and other research [30], those who should create solutions are mainly people with chronic diseases, as they are capable of identifying their own needs.

\section{REFERENCES}

1. Ilmarinen J. Work ability - a comprehensive concept for occupational health research and prevention. Scand J Work Environ Health. 2009;35(1):1-5, https://doi.org/10.5271/sjweh. 1304.

2. Jin-Won N, Jinseok K, Jumin P, Hyun-Jung K, Young Dae K. Gender Difference in Relationship between Health-Related Quality of Life and Work Status. Ginsberg SD, editors. PLoS One. 2015;10(12):e0143579, https://doi.org/10.1371/journal. pone. 0143579 .

3. Waddell G, Burton K. Is work good for your health and wellbeing? London: The Stationery Office; 2006 [cited 2018 Jun 5]. Available from: https://www.gov.uk/government/uploads/sys tem/uploads/attachment_data/file/214326/hwwb-is-workgood-for-you.pdf.

4. Schuring M, Mackenbach J, Voorham T, Burdorf A. The effect of re-employment on perceived health. J Epidemiol Community Heal. 2011;65(7):639-44, https://doi.org/10.1136/ jech.2009.103838.

5. Schwartz CE, Andresen EM, Nosek MA, Krahn GL. Response Shift Theory: Important Implications for Measuring Quality of Life in People With Disability. Arch Phys Med Rehabil. 2007;88(4):529-36, https://doi.org/10.1016/ j.apmr.2006.12.032.

6. Altman B. Factors in Studying Employment for Persons with Disability: How the picture can change. London: Emerald Publishing; 2017. p. 7-14.

7. World Health Organization [Internet]. Geneva: The Organization; 2001 [cited 2018 Jun 8]. International Classification of Functioning, Disability and Health (ICF). Available from: http://www.who.int/classifications/icf/en/.
8. Oliver M, Sapey B. Social Work with Disabled People. 2nd ed. London: Macmillan; 1999.

9. Priestley M. Disability Politics and Community Care. London: Jessica Kingsley Publisher; 1999.

10. French S. Disabled People and Employment, First. New York: Ashgate Publishing; 2001.

11. Shakespeare T, Watson N. Defending the Social Model Disabil. Soc. 1997;12(2):293-300, https://doi.org/10.1080/096875 99727380.

12. World Health Organization. Towards a Common Language for Functioning, Disability and Health ICF Towards a Common Language for Functioning, Disability and Health: ICF The International Classification of Functioning, Disability and Health [Internet]. Geneva: The Organization; 2002 [cited 2018 Apr 20]. Available from: http://www.who.int/classifications/icf/icfbeginnersguide.pdf.

13. Central Statistical Office. [Internet]. Warsaw: The Office; 2015 [cited 2018 Apr 4]. [Social Surveys and Living Conditions Department. Health Status of Population in Poland in 2014]. Available from: http://stat.gov.pl/obszary-tematyczne/zdrowie/zdrowie/stan-zdrowia-ludnosci-polski-w2014-r-,6,6.html. Polish.

14. Central Statistical Office [Internet]. Warsaw: The Office; 2018 [cited 2019 Mar 23]. [Labour force survey in Poland in I quarter 2018]. Avaliable from: https://stat.gov.pl/obsza ry-tematyczne/rynek-pracy/pracujacy-bezrobotni-bierni-zawodowo-wg-bael/aktywnosc-ekonomiczna-ludnosci-polski-ikwartal-2018-roku,4,29.html.Polish.

15. Central Statistical Office [Internet]. Warsaw: The Office; 2017 [cited 2019 Mar 23]. [Health and Health Care]. Avaliable from: https://stat.gov.pl/obszary-tematyczne/zdrowie/ zdrowie/zdrowie-i-ochrona-zdrowia-w-2017-r-,1,8.html. Polish.

16. Social Insurance Institution [Internet]. Warsaw: The Institution; 2015 [cited 2018 Apr 4]. [Expenditures on Social Security Benefits Related to Incapacity for Work]. Avaliable from: http:/www.zus.pl/baza-wiedzy/statystyka/ opracowania-tematyczne/wydatki-na-swiadczenia-z-ubez 
pieczen-spolecznych-zwiazane-z-niezdolnoscia-do-pracy. Polish.

17. European Commission [Internet]. Brussels: The Commission; 2014 [cited 2018 Mar 28]. The European Semester. Available from: http://ec.europa.eu/europe2020/europe2020-in-a-nutshell/priorities/inclusive-growth/index_en.htm. 18. National Programme for Protection of the Mental Health [Internet]. Warsaw: Ministry of Health; 2017 [cited 2019 Mar 24]. Available from: https://www.gov.pl/web/zdrowie/ narodowy-program-ochrony-zdrowia-psychicznego1.

19. [Act No. 887 of 13 October 1998 on the Social Insurance System. J Laws 1998-11-10, No. 137, pp.4850-80]. Polish.

20. [Act of 27 August 1997 on Vocational and Social Rehabilitation and Employment of Persons with Disabilities. J Laws 1997, item 123]. Polish.

21. [Labour Code of 26 June 1974. J Laws 1974, No. 24, item 141). Polish.

22. Scaratti C, Leonardi M, Silvaggi F, Avila C, Munoz-Murillo A, Stavroussi P, et al. Mapping European Welfare Models: State of the Art of Strategies for Professional Integration and Reintegration of Persons with Chronic Diseases. Int J Environ Res Public Health. 2018;15(4):781, https://doi. org/10.3390/ijerph15040781.

23. Baanders AN, Mieke Rijken P, Peters L. Labour participation of the chronically ill: a profile sketch. Eur J Public Health. 2002;12(2):124-30, https://doi.org/10.1093/eurpub/ 12.2.124.

24. Munir F, Jones D, Leka S, Griffiths A. Work limitations and employer adjustments for employees with chronic illness. Int J Rehabil Res. 2005;28(2):111-7, https://doi. org/10.1097/00004356-200506000-00003.

25. Vooijs M, Leensen MCJ, Hoving JL, Wind H, Frings-Dresen MHW. Interventions to enhance work participation of workers with a chronic disease: a systematic review of reviews. Occup Environ Med. 2015;72(11):820-6, https://doi.org/ 10.1136/oemed-2015-103062.
26. Waddell G, Burton AK, Kendell N. Vocational Rehabilitation. What Works for Whom? London: University of Huddersfield Repository Waddell; 2005.

27. Grover C, Piggott L. Disabled People, Work and Welfare: Is Employment Really the Answer? Bristol: Policy Press; 2015.

28. Fundacja Instytut Rozwoju Regionalnego. [Benefit trap and work activity of people with disability] [Internet]. Kraków: Fundacja; 2011 [cited 2018 Jun 5]. Avaliable from: http:// www.firr.org.pl/uploads/PUB/Pulapka_swiadczeniowa.pdf. Polish.

29. Burns T, Catty J, Becker T, Drake RE, Fiortti A, Knapp M, et al. The effectiveness of supported employment for people with severe mental illness: a randomised controlled trial. Lancet. 2007;370(9593):1146-52, https://doi.org/10.1016/S01406736(07)61516-5.

30. Van Hal LBE, Meershoek A, de Rijk A, Nijhuis F. Going beyond vocational rehabilitation as a training of skills: returnto-work as an identity issue. Disabil Soc. 2012;27(1):81-93, https://doi.org/10.1080/09687599.2012.631799.

31. Vooijs M, Leensen MCJ, Hoving JL, Wind H, Frings-Dresen MHW. Perspectives of People with a Chronic Disease on Participating in Work: A Focus Group Study. J Occup Rehabil. 2017;27(4):593-600, https://doi.org/10.1007/s10926016-9694-6.

32. Foreman P, Murphy G, Swerissen H. Facilitators and Barriers to Return to Work: A Literature Review. Melbourne: Australian Institute for Primary Care, La Trobe University; 2006.

33. Hyde M. From Welfare to Work? Social Policy for Disabled People of Working Age in the United Kingdom in the 1990s. Disabil Soc. 2000;15(2):327-41, https://doi.org/10. 1080/09687590025702.

34. Sprangers MA., Schwartz CE. Integrating response shift into health-related quality of life research: a theoretical model. Soc Sci Med. 1999;48(11):1507-15, https://doi.org/10.1016/ S0277-9536(99)00045-3.

This work is available in Open Access model and licensed under a Creative Commons Attribution-NonCommercial 3.0 Poland License - http://creativecommons.org/ licenses/by-nc/3.0/pl/deed.en. 